Article

\title{
Hybrid Molecular Compound Exhibiting Slow Magnetic Relaxation and Electrical Conductivity
}

\author{
Yongbing Shen ${ }^{1}$, Goulven Cosquer ${ }^{1,2}$, Brian K. Breedlove ${ }^{1}$ and Masahiro Yamashita ${ }^{1,2,3, *}$ \\ 1 Department of Chemistry, Graduate School of Science, Tohoku University, Aramaki-Aza-Aoba, Aoba-ku, \\ Sendai 980-8578, Japan; shenyongbing17@gmail.com (Y.S.); cosquer.g@m.tohoku.ac.jp (G.C.); \\ breedlove@m.tohoku.ac.jp (B.K.B.) \\ 2 Core Research for Evolutional Science and Technology (CREST), Japan Science and Technology (JST), \\ 4-1-8 Kawaguchi, Saitama 332-0012, Japan \\ 3 WPI Research Center, Advanced Institute for Materials Research, Tohoku University, 2-1-1 Katahira, \\ Aoba-ku, Sendai 980-8577, Japan \\ * Correspondence: yamashita.m@gmail.com; Tel.: +81-22-765-6547
}

Academic Editor: Kevin Bernot

Received: 27 September 2016; Accepted: 30 November 2016; Published: 9 December 2016

\begin{abstract}
Electrochemical oxidation of a solution containing $\mathrm{KDy}(\mathrm{hfac})_{4}$ (hfac, hexafluoroacetyacetone) and Bis(ethylenedithio)tetrathiafulvalene (BEDT-TTF) afforded a hybrid material formulated as $\left[\beta^{\prime}-(\mathrm{BEDT}-\mathrm{TTF})_{2} \mathrm{Dy}\left(\mathrm{CF}_{3} \mathrm{COO}\right)_{4} \cdot \mathrm{MeCN}\right]_{n}$. The complex crystallizes in the triclinic space group $P \overline{1}$. The before mentioned complex has a chain structure containing $4 f$ ions bridged by mono-anion $\mathrm{CF}_{3} \mathrm{COO}^{-}$ligand, and acts as single-molecule magnet (SMM) at low temperature. The conducting layer was composed of partially oxidized BEDT-TTF molecules in $\beta^{\prime}$ type arrangement. The presence of radical cation and its charge ordering was assigned on the basis of optical spectra. Electrical resistivity measurements revealed semiconducting behaviour (conductivity at room temperature of $1.1 \times 10^{-3} \mathrm{~S} \cdot \mathrm{cm}^{-1}$, activation energy of $158.5 \mathrm{meV}$ ) at ambient pressure.
\end{abstract}

Keywords: BEDT-TTF; conductivity; SMM; dysprosium

\section{Introduction}

Hybrid molecular materials combining conductivity (delocalized electrons or holes) and magnetism (localized electrons) have been intensively studied in the past decades, in order to observe a synergy between these properties [1-5]. Organic conductors, such as bis(ethylenedithio)tetrathiafulvalene (BEDT-TTF), and $\mathrm{M}(\mathrm{dmit})^{-}$(M: 3d or 4d metal; dmit: 4,5-dimercapto-1,3-dithiole-2-thione) with $\pi$ electrons have been widely used in conducting materials, affording a large number of superconductors [3], such as paramagnet/superconductor, anti-ferromagnet/superconductor, and ferromagnet/metal [6-8]. In recent years, research has been performed using a single-molecule magnet (SMM) as an electronic conductor or a valve. The molecule is placed between two gold electrodes, and it acts as an electron transport. In the case of polarized spin, the SMM acts as a valve in relation to its magnetic polarization [9].

In parallel, several groups have synthesized materials combining SMM behaviour and molecular conductivity [10-13]. SMMs are isolated molecules possessing individual large ground state spins and uniaxial anisotropies, which cause a finite energy barrier $(\Delta)$ between up and down spin states. SMMs are characterized by slow relaxation of magnetization and quantum phenomena, such as quantum tunnelling of magnetization (QTM), which can be used to design spintronics devices. However, since both SMM behaviour and superconductivity occur at low temperature (around $15 \mathrm{~K}$ or below), there is a possibility that both can occur at the same time.

Our work focused on this third strategy. In previously reported materials, SMMs acted as donors, and organic conductors acted as acceptors leading to coexistence of SMM behaviour and 
semi-conductivity but in a different temperature range. Here, we reversed the roles of the donor and acceptor. We report a hybrid material, $\left[\beta^{\prime}-(\mathrm{BEDT}-\mathrm{TTF})_{2} \mathrm{Dy}\left(\mathrm{CF}_{3} \mathrm{COO}\right)_{4} \cdot \mathrm{MeCN}\right]_{n}(\mathbf{1})$, with an anionic Dy ${ }^{\text {III }}$ complex exhibiting slow relaxation of magnetisation and the organic conductor BEDT-TTF. To the best of our knowledge, this is one of few works in which slow relaxation of the magnetization from an $f$ ion and molecular semi-conductivity have been combined [14].

\section{Results}

The electrochemical oxidation of BEDT-TTF and cocrystallisation with Dy(hfac) ${ }_{4}$ (hfac, hexafluoroacetyacetone) afforded the polymeric complex (1). The degradation of Dy(hfac $)_{4}$ to $\left\{\mathrm{Dy}\left(\mathrm{CF}_{3} \mathrm{COO}\right)_{4}\right\}_{n}$ occurred when a non-dry solvent was used. The water in the solvent along with the catalytic action of the dc current decomposed the hfac ${ }^{-}$ligand to $\mathrm{CF}_{3} \mathrm{COCH}_{3}$ and $\mathrm{CF}_{3} \mathrm{COO}^{-}$[15].

\subsection{Crystal Structure}

Compound (1) crystallised in the triclinic $P \overline{1}$ space group (Table S1, Figure S1) with two BEDT-TTF units, one $\left[\mathrm{Dy}\left(\mathrm{CF}_{3} \mathrm{COO}\right)_{4}\right]^{-1}$ unit and one acetonitrile molecule in the asymmetric unit (Figure 1). The crystal packing had alternating organic and inorganic layers along the $c$ axis (Figure 2). The inorganic layer contains "zig-zag" chains of dysprosium ions bridged by deprotonated trifluoroacetic acid ligands to form a paddle wheel infinite chain. The coordination sphere of the dysprosium ions has a quasi-perfect $D_{4 \mathrm{~d}}$ symmetry (deviation of 0.029 obtained by SHAPE $[16,17]$ ) composed of eight oxygen atoms (Table S2). The distance between adjacent dysprosium metals was determined to be $4.424 \AA$ and $4.548 \AA$ with a zig-zag angle of $151.83^{\circ}$. The chains are stacked parallel along the $b$ axis with an inter-chain distance of $11.541 \AA$. The inorganic layers were separated by $24.05 \AA$ along the $c$ axis. The organic layer contains BEDT-TTF molecules in a $\beta^{\prime}$-phase [18-20]. In this layer (Figure 3), the short $S \cdots S$ distance helped to form a ladder-like motif with distances in the range of 3.341-3.643 $\AA$, which are shorter than the sum of the Van der Waals radii ( $3.7 \AA$ ). The charges of each BEDT-TTF molecule were estimated to be +0.22 and +0.59 [21]. This total charge of +0.81 is smaller than the theoretical charge of +1 imposed by the electroneutrality of the complex. The charge was determined only on the basis of the distance between the atoms of the BEDT-TTF core. Interactions between the molecules deform the core (elongation or compression of the bonds), which affects the estimation of the charge, explaining the difference between the estimated and theoretical charges. This estimation is just a tool to describe the charge repartition in the material and therefore, it may not be accurate. Moreover, $\mathrm{X}$-ray diffraction affords an averaged structure, meaning that the charge is not estimated from a single molecule but from an averaged molecule. This averaging explains the non-integer charge of each BEDT-TTF.
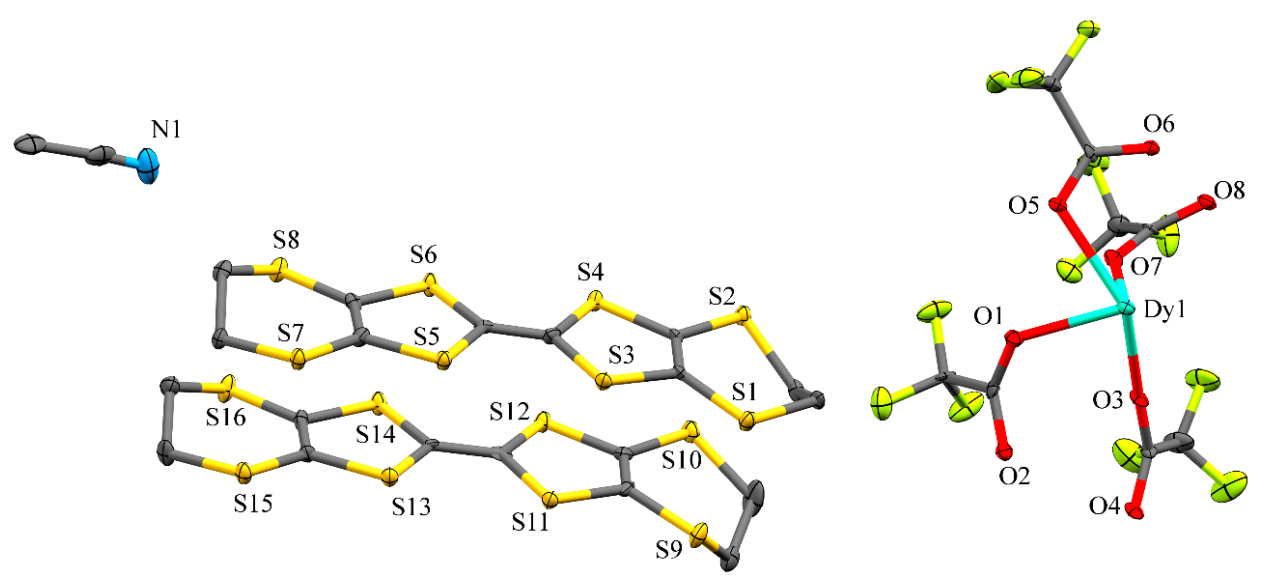

Figure 1. Asymmetric unit of $\left[\beta^{\prime}-(\mathrm{BEDT}-\mathrm{TTF})_{2} \mathrm{Dy}\left(\mathrm{CF}_{3} \mathrm{COO}\right)_{4} \cdot \mathrm{MeCN}\right]_{\mathrm{n}}(\mathbf{1})$ with hydrogen atoms omitted for clarity. 
a)

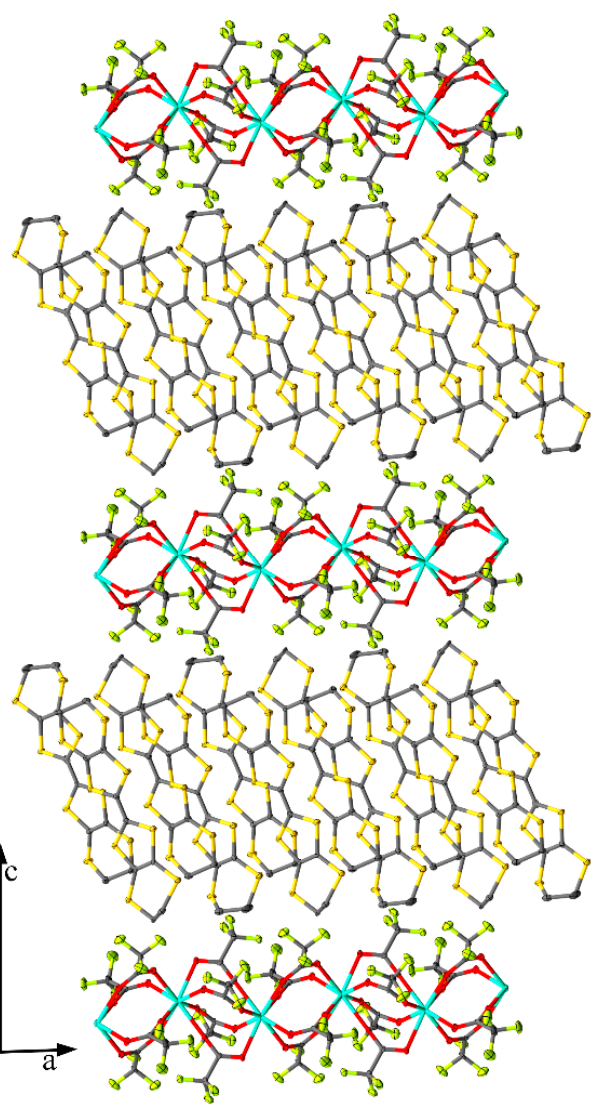

b)

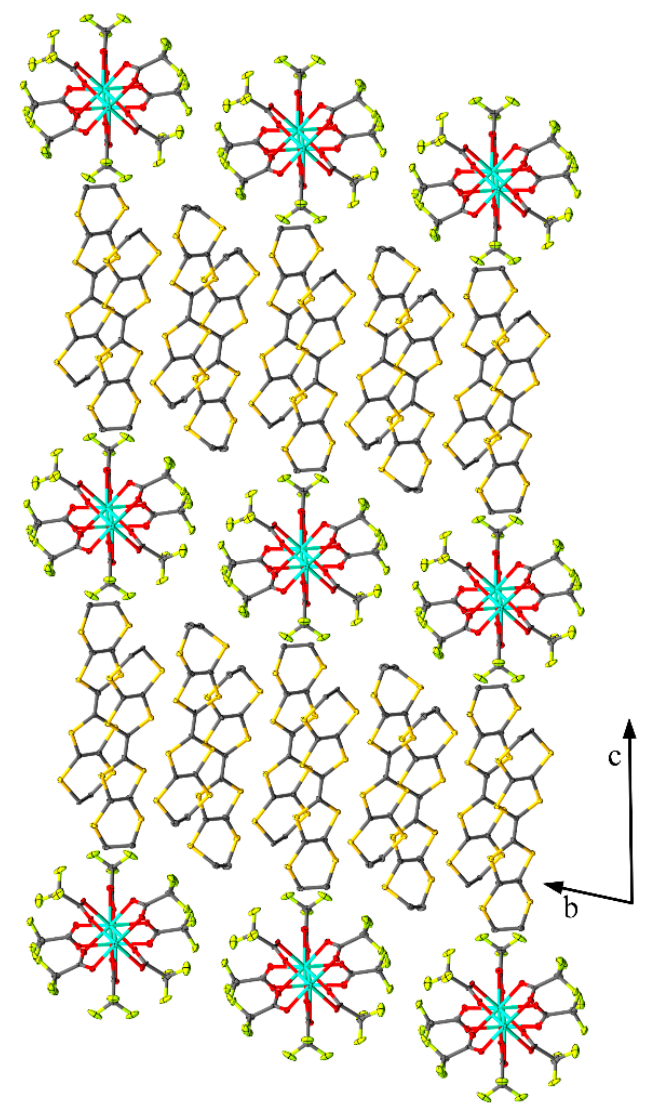

Figure 2. Packing structure in (a) the $a c$ and (b) $b c$ planes. Solvent molecule and hydrogen atoms were omitted for clarity.

a)
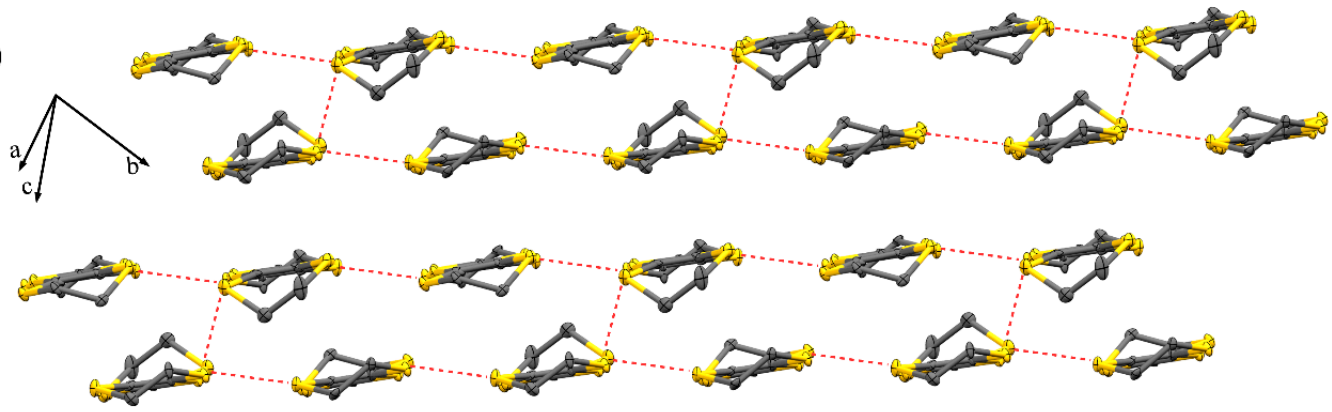

b)

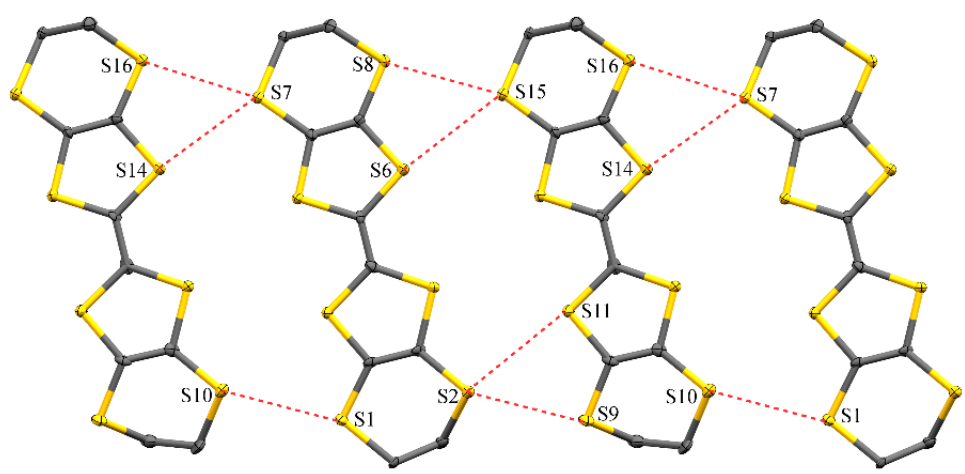

Figure 3. (a) View of the $\beta^{\prime}$-phase packing where the short S...S intermolecular contacts are highlighted by red dashed lines and $(\mathbf{b})$ details of one of the sheets. 


\subsection{Optical Properties}

In the UV-Vis spectra of (1), a strong absorption peak was observed centred at $980 \mathrm{~nm}$ (Figure S2), which was attributed to the electron transition from SOMO-1 to SOMO of BEDT-TTF ${ }^{+}$. This absorption peak is evidence for a radical in (1), which agrees with the total charge of 0.81 electrons estimated from the crystal structure. In the higher energy region, the absorption peak at $461 \mathrm{~nm}$ was ascribed to a $\pi-\pi^{*}$ transition of BEDT-TTF ${ }^{+}[22,23]$.

In order to investigate the electronic structure of (1), polarized IR reflectance spectra were acquired at $300 \mathrm{~K}$. The spectra were polarized along the BEDT-TTF stacking direction, and the electrical vector was parallel to the [110] direction (Figure 4). The broad peak around $3500 \mathrm{~cm}^{-1}$ was attributed to an intermolecular charge transfer (CT) between two (BEDT-TTF) ${ }^{\bullet+}$ moieties. In the $900-1800 \mathrm{~cm}^{-1}$ region, the three peaks $\left(1672 \mathrm{~cm}^{-1}, 1349 \mathrm{~cm}^{-1}\right.$ and $\left.1270 \mathrm{~cm}^{-1}\right)$ were attributed to the $v_{27}$ stretching mode of neutral BEDT-TTF molecule and the $v_{3}$ stretching mode of the radical BEDT-TTF molecule. The broad maximum around $1300 \mathrm{~cm}^{-1}$ was attributed to an electron-molecular vibrational (e-mv) interaction due to coupling between intermolecular $\mathrm{CT}$ and $\mathrm{C}=\mathrm{C}$ stretching modes.

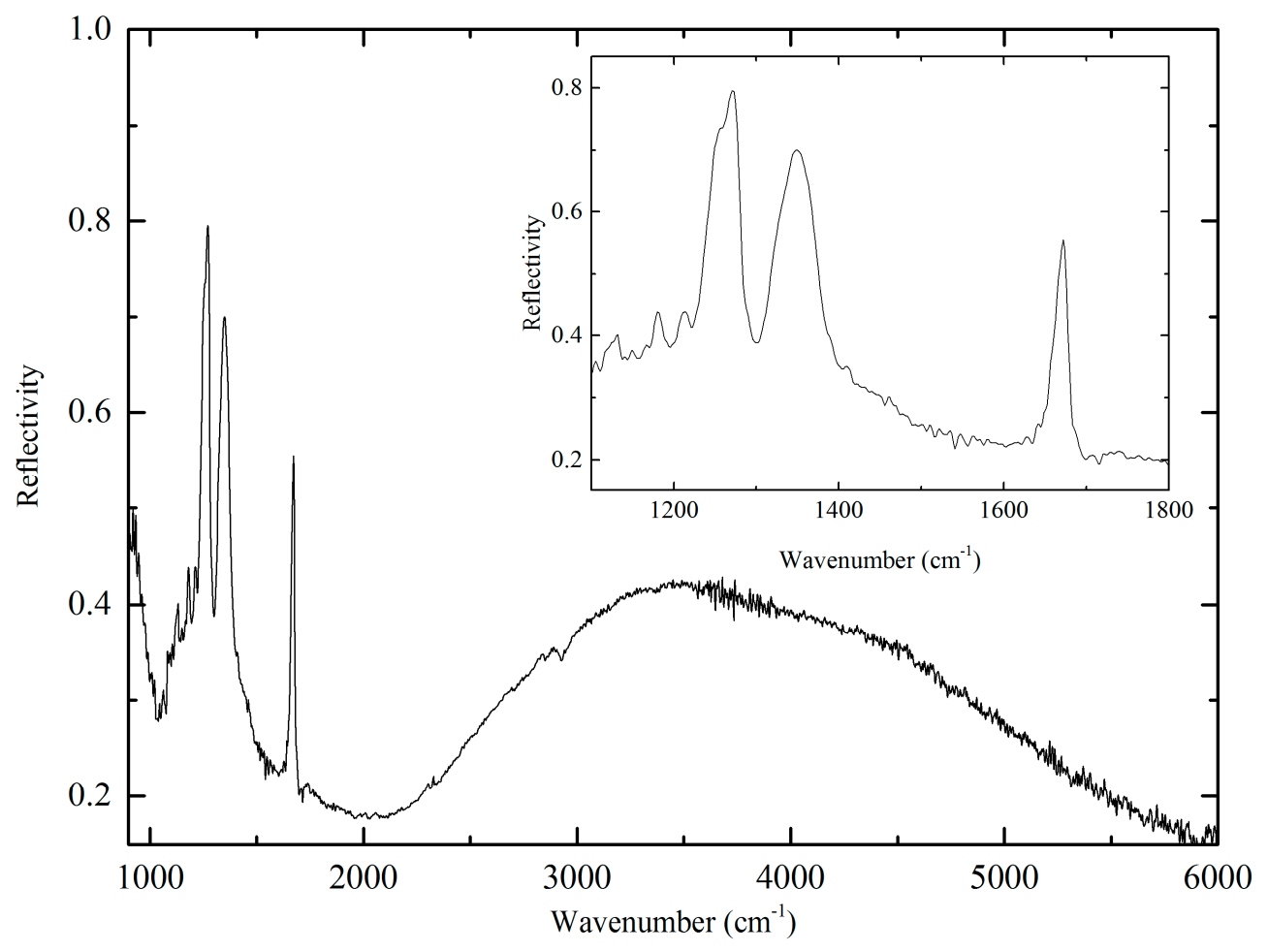

Figure 4. Polarized IR reflectance spectrum at $300 \mathrm{~K}$.

The electronic state of the BEDT-TTF molecules were estimated from the position and intensity of vibration peaks $[24,25]$. The charges of the BEDT-TTF molecules obtained from X-ray crystal structure analyses and the polarized IR measurement agree with each other with charge ordering of one neutral BEDT-TTF molecule and one radical cation BEDT-TTF molecule along the [110] direction. The charge-ordered state is supported by the electrical resistivity [26-31].

\subsection{Electrical Conductivity}

The electronic conductivity of the single-crystal was measured using a two-probe method in the temperature range of 300-100 K (Figure S3). Below $100 \mathrm{~K}$, the conductivity of the crystals was out of the range for our equipment. In (1), semiconductor behaviour was shown along the $b$ axis. The conductivity at room temperature $\left(\sigma_{\mathrm{rt}}\right)$ was $1.7 \times 10^{-3} \mathrm{~S} \cdot \mathrm{cm}^{-1}$ and decreased gradually with a decrease in temperature. The activation energy $\left(E_{\mathrm{a}}\right)$ between the valence and conduction bands was 
calculated to be $158.5 \mathrm{meV}$ at ambient pressure. Magneto-resistance has been investigated but not clearly observed due to the high resistance of the sample and/or limitation of our equipment.

Applying isostatic pressure in the range 0.4-2.2 GPa induced a continuous increase of three orders of magnitude in the conductivity at $100 \mathrm{~K}$ (Figure 5). $E_{a}$ decreased gradually with an increase in the pressure. This decrease in $E_{a}$ indicates an enhancement in the conduction band [32], which is attributed to isostatic compression of the BEDT molecule and an increase in the overlap of the molecular orbitals. Another possibility is a structural re-arrangement of the molecule, especially a change in the dihedral angle between neighbouring molecules which causes an overlap in the orbitals, which reduces $E_{a}$ [33].

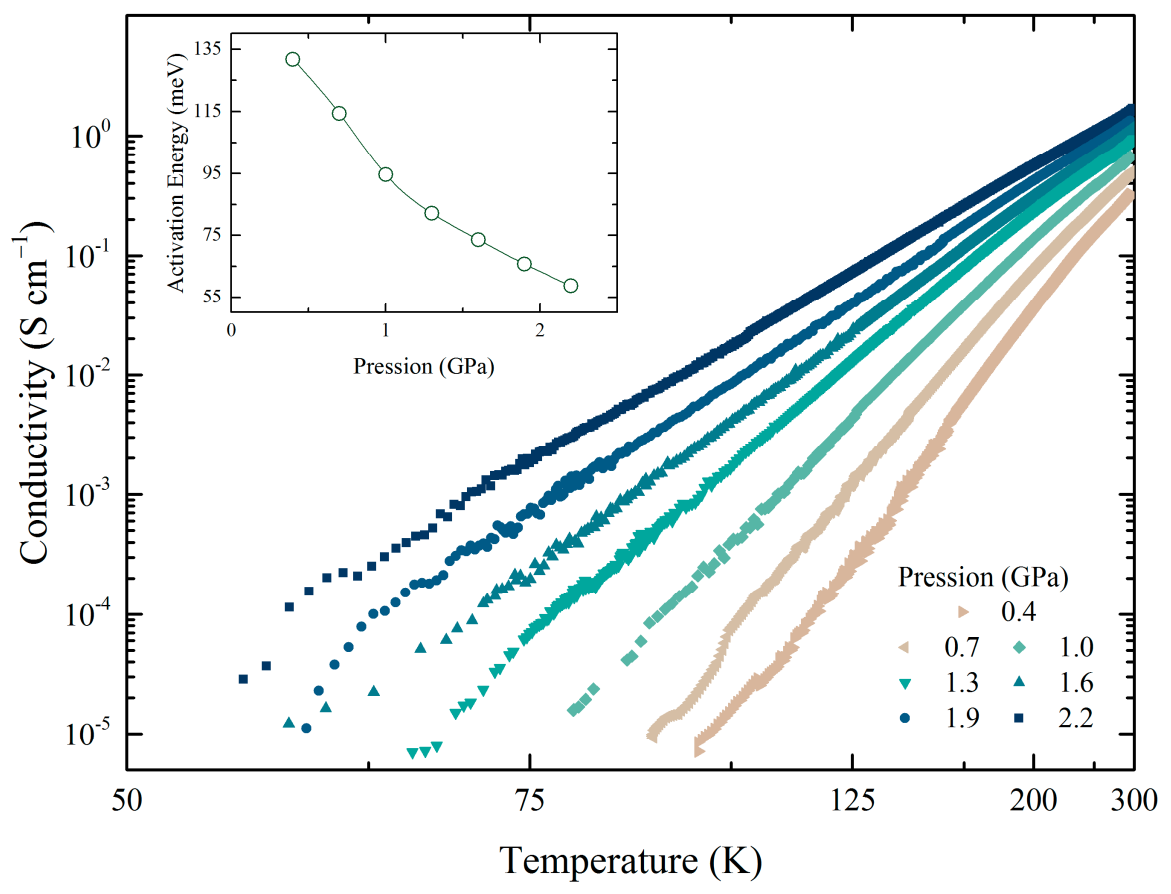

Figure 5. Temperature and pressure dependence of the conductivity. In the insert, the activation energy versus pressure.

\subsection{Magnetic Properties}

The temperature dependence of the static magnetic susceptibility $(\chi)$ was measured on a polycrystalline sample by applying a field of 1000 Oe (Figure 6). The $\chi T$ value of $13.30 \mathrm{~cm}^{3} \cdot \mathrm{K} \cdot \mathrm{mol}^{-1}$ at $300 \mathrm{~K}$ was significantly lower than the expected value of $14.545 \mathrm{~cm}^{3} \cdot \mathrm{K} \cdot \mathrm{mol}^{-1}$ for non-interacting radicals and free $\mathrm{Dy}^{3+}$ ions. This difference can be attributed to a preferencial orientation of the crystallite, which induce a deviation from the expected isotrope value [34]. $\chi T$ gradually decreased when the temperature was decreased, reaching a minimum value of $10.15 \mathrm{~cm}^{3} \cdot \mathrm{K} \cdot \mathrm{mol}^{-1}$ at $7.5 \mathrm{~K}$. Then it increased to a value of $10.94 \mathrm{~cm}^{3} \cdot \mathrm{K} \cdot \mathrm{mol}^{-1}$ at $2 \mathrm{~K}$. This increase below $7.5 \mathrm{~K}$ was attributed to dipole-dipole interactions between BEDT-TTF cation radicals and/or Dy ions [35]. Analysis of the $\ln (\chi T)$ versus $1 / T$ plots shows two linear regimes in the range of $7-5.5 \mathrm{~K}$ and $5-2 \mathrm{~K}$, which were fit with the equation $\chi T=\mathrm{C}_{\text {eff }} \times \mathrm{e}^{\Delta / \mathrm{kT}}$ (Figure S4). Nevertheless, the values of $\Delta$ are very small and are not clear evidence of single-chain magnet (SCM) behaviour for this complex. Interaction(s) such as dipole-dipole interaction definitely occur between the ions that exist in this compound but they are not strong enough to cause long-range ordering of the magnetic moment, characteristic of SCMs [36]. 


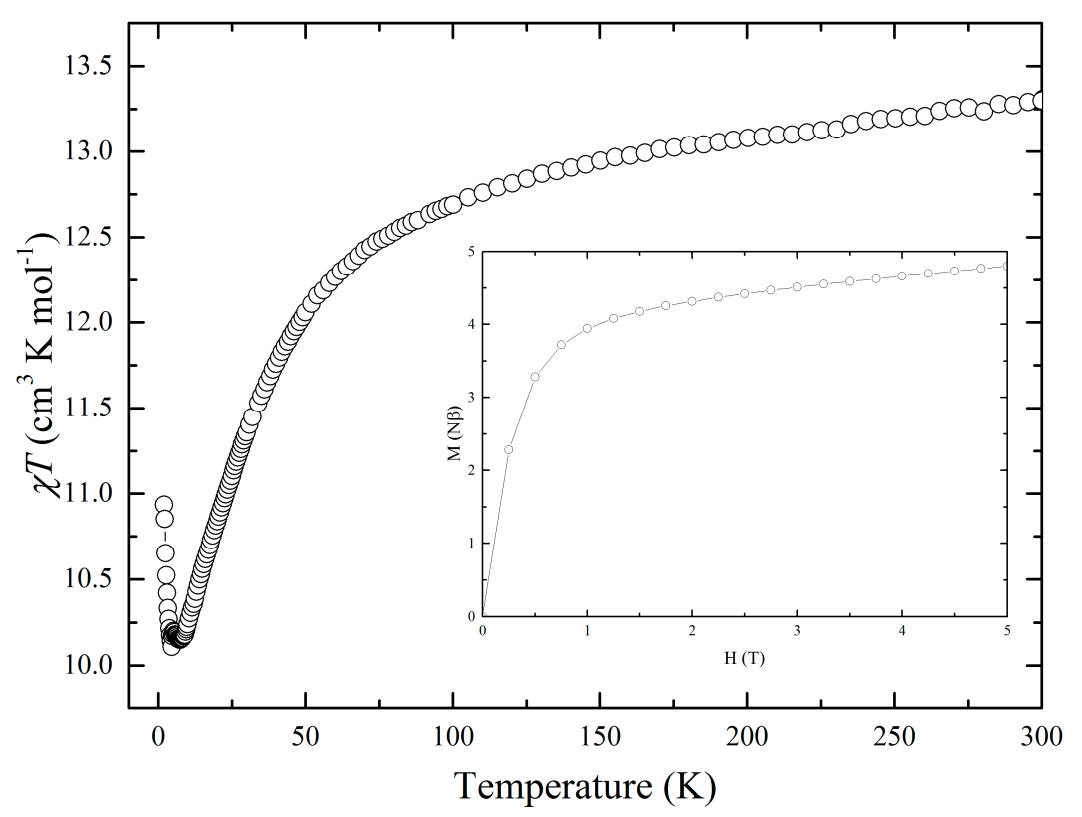

Figure 6. Temperature dependence of $\chi T$ for a polycrystalline sample. Insert shows the magnetisation curve at $1.85 \mathrm{~K}$.

The magnetisation curve exhibited pseudo-saturation from $1.5 \mathrm{~T}$ with a linear slope of $0.16 \mathrm{~N} \cdot \beta^{-1}$, reaching a value of $4.81 \mathrm{~N} \cdot \beta$ at $5 \mathrm{~T}$ (insert of Figure 6). No hysteresis was observed.

The dynamic susceptibility exhibited weak temperature and frequency dependences below $5 \mathrm{~K}$ (Figures S5-S7 and Table S3). However, distinct out-of-phase peaks were not observed over the full temperature range up to $1000 \mathrm{~Hz}$ due to the merging of two relaxation times. The data was analysed by using dual relaxation Cole-Cole model with one of the peaks over $1000 \mathrm{~Hz}$ and the adiabatic susceptibility set to zero [37]. The faster process, which was completely out of range, was used only to allow us to determine the nature of the slower process: a combination of Orbach and quantum tunnelling of the magnetisation (QTM) (Table 1). By applying an external magnetic field, it was possible to partially unmerge the two peaks (Figure S8) with an optimal field at 1000 Oe (Figures 7 and S9 and Table S4). With and without external field, the second peak was out of the range of our equipment and could not be determined accurately enough to be discussed here. The field suppresses the QTM and allows the system to relax though a direct and Orbach process (Figure 8). As expected, the energy barrier and the pre-exponential factor are comparable with and without a field and are comparable with other Dy III SMMs [37]. A Raman relaxation process has been considered to be a possible mechanism. However, it does not match with the experimental data. The origin of the two peaks is still unclear, and further studies are needed. Preparation of a diamagnetic doped compound has been tried to investigate the role of the dipole interactions in the relaxation process. However, it has been unsuccessful so far.

Table 1. Detail information about magnetic properties.

\begin{tabular}{ccc}
\hline Field & 0 Oe & 1000 Oe (Low f ) \\
\hline Calculation Equation & $\tau^{-1}=\frac{1}{\tau_{0}} \exp \left(\frac{-\Delta}{k_{B} T}\right)+\mathrm{QTM}$ & $\tau^{-1}=\frac{1}{\tau_{0}} \exp \left(\frac{-\Delta}{k_{B} T}\right)+\mathrm{AH}^{4} T^{2}$ \\
A & - & $3.3 \times 10^{-12}$ \\
$\tau 0(\mathrm{~s})$ & $8.8 \times 10^{-8}$ & $5.0 \times 10^{-8}$ \\
$\Delta\left(\mathrm{cm}^{-1}\right)$ & 21.3 & 22.1 \\
QTM $(\mathrm{s})$ & $1.1 \times 10^{-3}$ & - \\
\hline
\end{tabular}




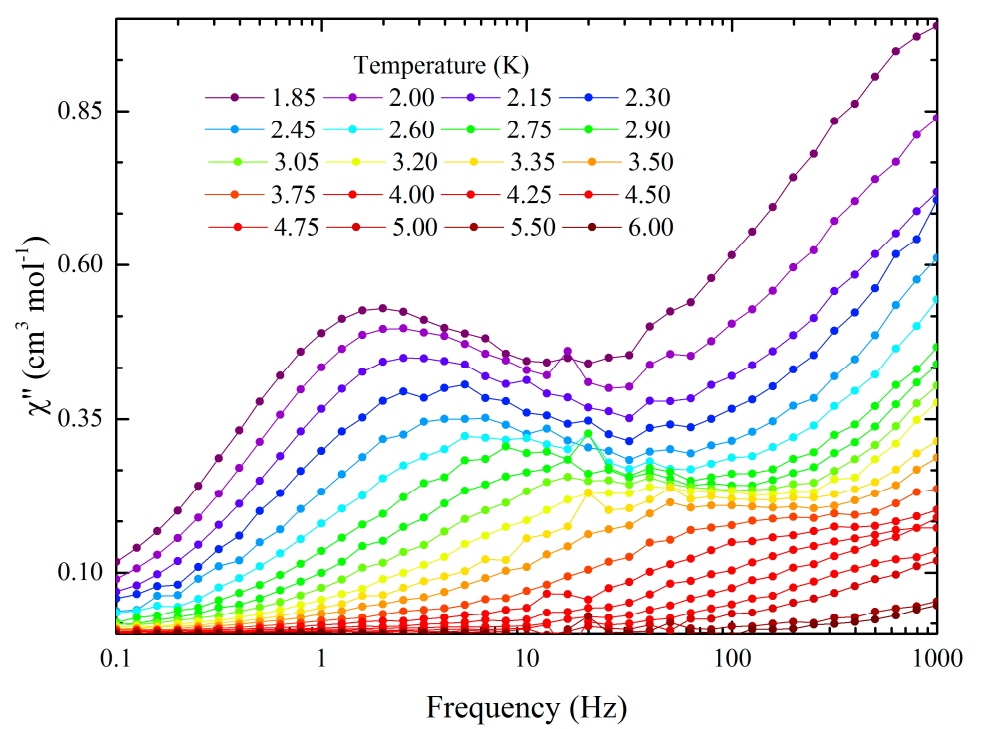

Figure 7. Frequency dependence of the out-of-phase magnetic susceptibility in a 1000 Oe field as a function of temperature.

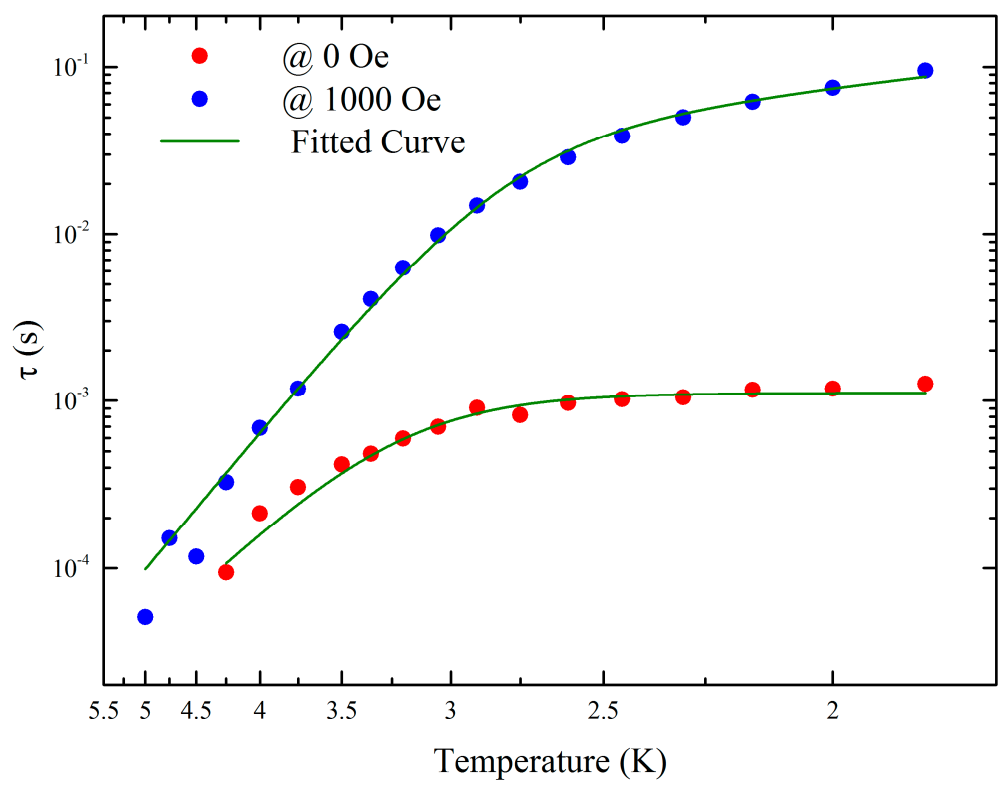

Figure 8. Temperature dependence of relaxation time in 0 and 1000 Oe dc fields.

\section{Materials and Methods}

\subsection{Synthesis}

Solvents were used without further purification. $\mathrm{KDy}(\mathrm{hfac})_{4}$ was prepared following the reported methods [38]. BEDT-TTF was purchased from TCI Tokyo Chemical Industry Co., LTD, Tokyo, Japan.

$\left[\beta^{\prime}-(\mathrm{BEDT}-\mathrm{TTF})_{2} \mathrm{Dy}\left(\mathrm{CF}_{3} \mathrm{COO}\right)_{4} \cdot \mathrm{MeCN}_{n}\right.$ (1). Single crystals of (1) were synthesized by using electrochemical oxidation. To an acetonitrile solution $(10 \mathrm{~mL})$ of $\mathrm{KDy}(\mathrm{hfac})_{4}(100 \mathrm{mg}, 0.1 \mathrm{mmol})$ and 18-crown-6-ether (100 mg, $0.38 \mathrm{mmol})$, a dichloromethane solution (15 mL) of BEDT-TTF (12 mg, $0.03 \mathrm{mmol}$ ) was slowly added. The mixture was stirred for $1 \mathrm{~h}$ to produce an orange brown solution. Black plate crystals suitable for X-ray analysis (CCDC 1506816) and resistivity measurements were obtained at the anode after few days by applying a constant current of $0.7 \mu \mathrm{A}$. Crystals were washed 
with methanol and dried in the air (yield: $7.84 \mathrm{mg} 5.7 \mu \mathrm{mol}, 5.7 \%)$. IR $\left(\mathrm{cm}^{-1}\right)$ : 1770, 1665, 1457, 1326, 1290, 1209.

\subsection{Physical Measurements}

UV-Vis spectra were acquired for solid-state samples, using a KBr disk, on a Shimadzu UV-3100pc (Shimadzu, Kyoto, Japan). Reflectance IR spectra were acquired on a JASCO IRT-5000 microscope and a FT-IR-6200YMS Infrared spectrometer (JASCO, Tokyo, Japan) in the ac plane of a single crystal with an angle of $60^{\circ}$ with the surface.

Magnetic susceptibility measurements were conducted using a Quantum Design SQUID magnetometer MPMS-5L (Quantum Design, San Diego, CA, USA) in the temperature and dc field ranges of $1.8-300 \mathrm{~K}$ and $-5-5 \mathrm{~T}$, respectively. AC measurements were performed at frequencies in the range of $0.1-1000 \mathrm{~Hz}$ with an ac field amplitude of $3 \mathrm{Oe}$. A polycrystalline sample embedded in n-eicosane was used for the measurements.

The temperature dependence of the electrical resistivity was measured using a Quantum Design PPMS 6000 (Quantum Design, San Diego, CA, USA) with an external Keithley 2611 System SourceMeter (Keithley Instruments, Solon, OH, USA) by using a two-probe method at ambient pressure. Gold wires (15 $\mu \mathrm{m}$ diameter) were attached to the crystal with carbon paste.

The electrical resistivity under pressure was measured with a Be-Cu clamp-type cell using a four-probe method. Pressure was applied via Daphne 7373 oil at room temperature and clamped with screws. The pressure value decreases by $0.2 \mathrm{GPa}$ at low temperatures compared to that at room temperature.

Single-crystal crystallographic data were collected at $103 \mathrm{~K}$ on a Rigaku Saturn70 CCD Diffractometer (Rigaku, Tokyo, Japan) with graphite-monochromated Mo K $\alpha$ radiation $(\lambda=0.71075 \AA)$ produced using a VariMax microfocus $X$-ray rotating anode source. A single crystal with dimensions of $0.20 \times 0.07 \times 0.01 \mathrm{~mm}^{3}$ was used. Data processing was performed using the Crystal Clear crystallographic software package [39]. The structures were solved by using direct methods using SIR-92 [40]. Refinement was carried out using WinGX 2013.3 package [41] and SHELXL-2013 [42]. The non-H atoms were refined anisotropically using weighted full-matrix least squares on $\mathrm{F}$. $\mathrm{H}$ atoms attached to the $\mathrm{C}$ atoms were positioned using idealized geometries and refined using a riding model.

Powder X-ray diffraction was performed on a Bruker AXS D2 phaser (Bruker Corporation Billerica, MA, USA).

\section{Conclusions}

Hybrid material (1) composed of an anionic magnetic chain layer and 2D cationic conducting layer (with the anionic/cationic configuration opposite to that previously reported), was prepared. The presence of a radical, centred on the BEDT-TTF, was evidenced by a strong SOMO $\rightarrow$ SOMO-1 transition in the UV-Vis spectra and by the electron-molecular vibrational interactions observed by using polarized IR spectroscopy. The conductivity at room temperature was determined to be $1.7 \times 10^{-3} \mathrm{~S} \cdot \mathrm{cm}^{-1}$ with an activation energy of $158.5 \mathrm{meV}$. Slow relaxation of the magnetisation was clearly observed in a 1000 Oe without any hysteresis. No correlation between conductivity and magnetism was observed due to the difference in temperature ranges for each property. This preliminary study has provided us with significant information for designing new hybrid materials based on quantum magnets and molecular conductors by increasing the molecular interactions between them. In the future, particular attention will be paid to the substitution of the trifluoro-methyl group.

Supplementary Materials: The following are available online at www.mdpi.com/2312-7481/2/4/44/s1, Figure S1: Powder X-ray diffraction spectra for 1, Figure S2: UV-Vis Spectra, Figure S3: Resistivity curve, Figure S4: Plots of $\ln (\chi T)$ versus 1/T, Figure S5: Temperature dependence of ac susceptibility measured in 0 Oe dc fields, Figure S6: Out-of-phase signal of the susceptibility of complex 1 without external field, Figure S7: Normalized Argand plot for complex 1 without external field, Figure S8: Frequency dependence of $\chi^{\prime \prime}$ at $1.85 \mathrm{~K}$ as a function of dc field, Figure S9: Normalized Argand plot for complex 1 in a 1000 Oe external field, Table S1: Crystallographic data for 1, Table S2: Coordination geometry deviation, Table S3: Fitting parameter of frequency dependence of 
susceptibility for $\mathbf{1}$ in 0 Oe field, Table S4: Fitting parameters for frequency dependence of susceptibility for $\mathbf{1}$ in a 1000 Oe field.

Acknowledgments: This work was financially supported by Core Research for Evolutional Science and Technology (CREST), Japan Science and Technology (JST). Yoji Horii and Takefumi Yoshida are acknowledged for their help with the solid-state UV-Vis and polarized IR measurements. In addition, we express our acknowledgement to Hiroshi Ito from the Department of Applied Physics, Nagoya University, Nagoya, Japan and his co-worker for the measurement of the pressure and temperature dependence of the conductivity.

Author Contributions: M.Y. conceived and designed the experiments; Y.S. performed the experiments; Y.S. and G.C. analyzed the data; Y.S., G.C. and B.K.B. wrote the paper.

Conflicts of Interest: The authors declare no conflict of interest. The founding sponsors had no role in the design of the study; in the collection, analyses, or interpretation of data; in the writing of the manuscript, and in the decision to publish the results.

\section{References}

1. Ouahab, L. Organic/inorganic supramolecular assemblies and synergy between physical properties. Chem. Mater. 1997, 9, 1909-1926. [CrossRef]

2. Enoki, T.; Miyazaki, A. Magnetic TTF-based charge-transfer complexes. Chem. Rev. 2004, 104, 5449-5478. [CrossRef] [PubMed]

3. Williams, J.M.; Ferraro, J.R.; Thorn, R.J.; Carlson, K.D.; Geiger, U.; Wang, H.H.; Kini, A.M.; Whangbo, M.H. Organic Superconductors: Synthesis, Structure, Properties and Theory; Grimes, R.N., Ed.; Prentice Hall: Englewood Cliffs, NJ, USA, 1992.

4. Martin, L.; Turner, S.S.; Day, P.; Mabbs, F.E.; McInnes, E.J.L. New molecular superconductor containing paramagnetic chromium (iii) ions. Chem. Commun. 1997, 15, 1367-1368. [CrossRef]

5. Fujiwara, H.; Fujiwara, E.; Nakazawa, Y.; Narymbetov, B.Z.; Kato, K.; Kobayashi, H.; Kobayashi, A.; Tokumoto, M.; Cassoux, P. A novel antiferromagnetic organic superconductor $k$-(BETS) ${ }_{2} \mathrm{FeBr}_{4}$ [Where BETS = Bis(ethylenedithio) tetraselenafulvalene]. J. Am. Chem. Soc. 2001, 123, 306-314. [CrossRef] [PubMed]

6. Yamaguchi, K.; Kitagawa, Y.; Onishi, T.; Isobe, H.; Kawakami, T.; Nagao, H.; Takamizawa, S. Spin-mediated superconductivity in cuprates, organic conductors and $\pi-\mathrm{d}$ conjugated systems. Coord. Chem. Rev. 2002, 226, 235-249. [CrossRef]

7. Day, P.; Kurmoo, M.; Mallah, T.; Marsden, I.R.; Friend, R.H.; Pratt, F.L.; Hayes, W.; Chasseau, D.; Gaultier, J.; Bravic, G.; et al. Structure and properties of tris[bis(ethylenedithio) tetrathiaful-valenium]tetrachlorocopper hydrate (BEDT-TTF) ${ }_{3} \mathrm{CuCl}_{4} \cdot \mathrm{H}_{2} \mathrm{O}$ : First evidence for coexistence of localized and conduction electrons in a metallic charge-transfer salt. J. Am. Chem. Soc. 1992, 114, 10722-10729. [CrossRef]

8. Ojima, E.; Fujiwara, H.; Kato, K.; Kobayashi, H.; Tanaka, H.; Kobayashi, A.; Tokumoto, M.; Cassoux, P. Antiferromagnetic Organic Metal Exhibiting Superconducting Transition, K-(BETS)2FeBr4 [BETS Bis(ethylenedithio) tetraselenafulvalene]. J. Am. Chem. Soc. 1999, 121, 5581-5582. [CrossRef]

9. Bogani, L.; Wernsdorfer, W. Molecular spintronics using single-molecule magnets. Nat. Mater. 2008, 7, 179-186. [CrossRef] [PubMed]

10. Kurmoo, M.; Graham, A.W.; Day, P.; Coles, S.J.; Hursthouse, M.B.; Caulfield, J.L.; Singleton, J.; Pratt, F.L.; Hayes, W.; Ducasse, L.; et al. Superconducting and Semiconducting Magnetic Charge Transfer Salt: (BEDT-TTF $)_{4} \mathrm{AFe}\left(\mathrm{C}_{2} \mathrm{O}_{4}\right)_{3} \mathrm{C}_{6} \mathrm{H}_{5} \mathrm{CN}\left(\mathrm{A}=\mathrm{H}_{2} \mathrm{O}, \mathrm{K}, \mathrm{NH}_{4}\right)$. J. Am. Chem. Soc. 1995, 117, 12209-12227. [CrossRef]

11. Hiraga, H.; Miyasaka, H.; Nakata, K.; Kajiwara, K.; Takaishi, S.; Oshima, Y.; Nojiri, H.; Yamashita, M. Hybrid molecular materials exhibiting single-molecule magnet behaviour and molecular conductivity. Inorg. Chem. 2007, 46, 9661-9671. [CrossRef] [PubMed]

12. Hiraga, H.; Miyasaka, H.; Takaishi, S.; Kajiwara, T.; Yamashita, M. Hybridized complexes of $\frac{1}{2}$ MnIII 2 single-molecule magnets and Ni dithiolate complexes. Inorg. Chim. Acta 2008, 361, 3863-3872. [CrossRef]

13. Kubo, K.; Shiga, T.; Yamamoto, T.; Tajima, A.; Moriwaki, T.; Ikemoto, Y.; Yamashita, M.; Sessini, E.; Mercuri, M.-L.; Deplano, P.; et al. Electronic state of a conducting single molecule magnet based on Mn-salen type and Ni-Dithiolene complexes. Inorg. Chem. 2011, 50, 9337-9344. [CrossRef] [PubMed]

14. Ueki, S.; Nogami, T.; Ishida, T.; Tamura, M. ET and TTF salts with lanthanide complex ions showing frequency-dependent ac magnetic susceptibility. Mol. Cryst. Liq. Cryst. 2006, 455, 129-134. [CrossRef]

15. Johnson, D.A.; Waugh, A.B.; Hambley, T.W.; Taylor, J.C. Synthesis and Crystal Structure of 1,1,1,5,5,5Hexafluoro-2-aminopentan-4-one (HFAP). J. Fluor. Chem. 1985, 27, 371-378. [CrossRef] 
16. Ruiz-Martínez, A.; Casanova, D.; Alvarez, S. Polyhedral structures with an odd number of vertices: Nine-coordinate metal compounds. Chem. Eur. J. 2008, 14, 1291-1303. [CrossRef] [PubMed]

17. Alvarez, S.; Alemany, P.; Casanova, D.; Cirera, J.; Llunell, M.; Avnir, D. Shape maps and polyhedral interconversion paths in transition metal chemistry. Coord. Chem. Rev. 2005, 249, 1693-1708.

18. Mori, T. Structural genealogy of BEDT-TTF-based organic conductors I. parallel molecules: $\beta$ and $\beta$ Phases. Bull. Chem. Soc. Jpn. 1998, 71, 2509-2526. [CrossRef]

19. Mori, T.; Mori, H.; Tanaka, S. Structural genealogy of BEDT-TTF-based organic conductors II. inclined molecules: $\theta, \alpha$, and $\kappa$ Phases. Bull. Chem. Soc. Jpn. 1999, 72, 179-197. [CrossRef]

20. Shibaeva, R.P.; Yagubskii, E.B. Molecular conductors and superconductors based on Trihalides of BEDT-TTF and some of its analogues. Chem. Rev. 2004, 104, 5347-5378. [CrossRef] [PubMed]

21. Guionneau, P.; Kepert, C.J.; Bravic, G.; Chasseau, D.; Truter, M.R.; Kurmoo, M.; Day, P. Determining the charge distribution in BEDT-TTF salts. Synth. Metal. 1997, 86, 1973-1974. [CrossRef]

22. Rosokha, S.V.; Kochi, J.K. Molecule and electronic structure of the long-bonded $\pi$-dimers of tetrathiafulvalene cation-radical in intermolecular electron transfer and in (solid-state) conductivity. J. Am. Chem. Soc. 2007, 129, 828-838. [CrossRef] [PubMed]

23. Cosquer, G.; Pointillart, F.; Le Guennic, B.; Le Gal, Y.; Golhen, S.; Cador, O.; Ouahab, L. 3d4f heterobimetallic dinuclear and tetranuclear complexes. Inorg. Chem. 2012, 51, 8488-8501. [CrossRef] [PubMed]

24. Pokhodnya, K.I.; Cassoux, P.; Feltre, L.; Meneghtti, M. Optical excitations in a quarter-filled Ni(dmit) ${ }_{2}$ based compound described by a dimerized octamer model. Synth. Met. 1999, 103, 2187. [CrossRef]

25. Romaniello, P.; Lelj, F.; Arca, M.; Devillanova, F.A. Structural and new spectroscopic properties of neutral $\left[\mathrm{M}(\mathrm{dmit})_{2}\right]\left(\mathrm{dmit}=\mathrm{C}_{3 \mathrm{~S}_{5}}{ }^{2-}, 1,3\right.$-dithiole-2-thione-4,5-dithiolate $)$ and $\left[\mathrm{M}\left(\mathrm{H}_{2} \text { timdt }\right)_{2}\right]\left(\mathrm{H}_{2}\right.$ timdt $=\mathrm{H}_{2} \mathrm{C}_{3} \mathrm{~N}_{2} \mathrm{~S}_{3}{ }^{1-}$, monoanion of imidazolidine-2,4,5-trithione) complexes within the density functional approach. Theor. Chem. Acc. 2007, 117, 621-635. [CrossRef]

26. Visentini, G.; Masino, M. Experimental determination of BEDT-TTF electron-molecular vibration constants through optical microreflectance. Phys. Rev. B 1998, 58, 9460-9467. [CrossRef]

27. Tajima, H.; Yakushi, K.; Kuroda, H. Polarized reflectance spectrum of $\beta$-(BEDT-TTF $)_{2} \mathrm{I}_{3}$ single crystal. Solid State Commun. 1985, 56, 159-163. [CrossRef]

28. Yamamoto, T.; Uruichi, M.; Yamamoto, K.; Yakushi, K.; Kawamoto, A.; Taniguchi, H. Examination of the Charge-Sensitive Vibrational Modes in Bis(ethylenedithio)tetrathiafulvalene. J. Phys. Chem. B 2005, 109, 15226-15235. [CrossRef] [PubMed]

29. Yamamoto, T.; Nakazawa, Y.; Tamura, M.; Fukunaga, T.; Kato, R.; Yakushi, K. Vibrational Spectra of $\left[\mathrm{Pd}(\mathrm{dmit})_{2}\right]$ Dimer (dmit = 1,3-dithiole-2-thione-4,5-dithiolate): Methodology for examining charge, inter-molecular interactions, and orbital. J. Phys. Soc. Jpn. 2011, 80. [CrossRef]

30. Jacobsen, C.S.; Tanner, D.B. Electronic structure of some $p-\left(\mathrm{C}_{10} \mathrm{H}_{8} \mathrm{~S}_{8}\right) 2 \mathrm{X}$ compounds as studied by infrared spectroscopy. Phys. Rev. B. 1987, 35, 9605-9612. [CrossRef]

31. Świetlik, R.; Połomska, M.; Ouahab, L.; Guillevic, J. Infrared and Raman studies of the k-phase charge-transfer salts formed by BEDT-TTF and magnetic anions $\mathrm{M}(\mathrm{CN})_{6}{ }^{3-}$ (where $\mathrm{M}=\mathrm{Co}{ }^{\mathrm{III}}, \mathrm{Fe}^{\mathrm{III}}, \mathrm{Cr}{ }^{\mathrm{III}}$ ). J. Mater. Chem. 2001, 11, 1313-1318. [CrossRef]

32. Sugimoto, T.; Fujiwara, H.; Noguchi, S.; Murata, K. New aspects of $\pi-\mathrm{d}$ interactions in magnetic molecular conductors. Sci. Technol. Adv. Mater. 2009, 10, 024302. [CrossRef] [PubMed]

33. Alemany, P.; Pouget, J.-P.; Canadell, E. Structural and electronic control of the metal to insulator transition and local orderings in the $\theta-($ BEDT-TTF)2X organic conductors. J. Phys. Condens. Matter 2015, 27, 465702. [CrossRef] [PubMed]

34. Kahn, O. Molecular Magnetism; VCH Publishers: Weinheim, Germany, 1993.

35. Kinoshita, M.; Novoa, J.J.; Inoue, K.; Rawson, J.M.; Arčon, D. $\pi$-Electron Magnetism. From Molecules to Magnetic Materials; Veciana, J., Ed.; Springer: Berlin/Heidelberg, Germany, 2001.

36. Tian, H.; Wei, S.; Zheng, N.; Bo, N.; Peng, C. Magnetic blocking from exchange interactions: Slow relaxation of the magnetization and hysteresis loop observed in a dysprosium-nitronyl nitroxide chain compound with an antiferromagnetic ground state. Chem. Eur. J. 2013, 19, 994-1001.

37. Yatoo, M.A.; Cosquer, G.; Morimoto, M.; Irie, M.; Breedlove, B.K.; Yamashita, M. 1D chains of lanthanoid ions and a dithienylethene ligand showing slow relaxation of the magnetization. Magnetochemistry 2016, 2, 21. [CrossRef] 
38. Zeng, D.; Ren, M.; Bao, S.-S.; Zheng, L.M. Tuning the coordination geometries and magnetic dynamics of [Ln(hfac) $\left.]_{4}\right]^{-}$through alkali metal counterions. Inorg. Chem. 2014, 53, 795-801. [CrossRef] [PubMed]

39. Crystal Clear-SM, 1.4.0 SP1; Rigaku Corporation: Tokyo, Japan, 17 April 2008.

40. Altomare, A.; Burla, M.C.; Camalli, M.; Cascarano, G.L.; Giacovazzo, C.; Guagliardi, A.; Moliterni, A.G.G.; Polidori, G.; Spagna, R. SIR97: A new tool for crystal structure determination and refinement. J. Appl. Crystallogr. 1999, 32, 115-119. [CrossRef]

41. Farrugia, L.J. WinGX and ORTEP for Windows: An update. J. Appl. Crystallogr. 2012, 45, 849-854. [CrossRef]

42. Sheldrick, G.M. Crystal structure refinement with SHELXL. Acta Cryst. C 2015, 71, 3-8. [CrossRef] [PubMed]

(C) 2016 by the authors; licensee MDPI, Basel, Switzerland. This article is an open access article distributed under the terms and conditions of the Creative Commons Attribution (CC-BY) license (http://creativecommons.org/licenses/by/4.0/). 